\author{
기초학습부진으로 의뢰된 일 광역시의 일반학급 초등학생의 심리, \\ 정신과적 평가 및 부모의 특성 \\ 방수영 ${ }^{1)}$. 박정환 ${ }^{2)}$. 임재인 ${ }^{3)}$ \\ 울산대학교 의과대학 정신과학교실, ${ }^{1)}$ 굿마인드 의원, ${ }^{2)}$ 마더스병원 소아청소년 정신과 ${ }^{3)}$
}

\title{
Clinical Diagnoses, Psychopathology, and Neurocognitive Tests in Children Referred for Scholastic Difficulties and Their Parents
}

\author{
Soo-Young Bhang, M.D., M.P.H. ${ }^{1)}$, Jung-Whan Park, M.D. ${ }^{2)}$ and Jae-In Lim, M.D. ${ }^{3)}$ \\ ${ }^{1)}$ Department of Psychiatry, University of Ulsan, College of Medicine, Ulsan, Korea \\ ${ }^{2)}$ Ulsan Goodmind Clinic, Ulsan, Korea \\ ${ }^{3)}$ Department Child and Adolescent Psychiatry, Motherth Hospital, Ulsan, Korea
}

Objectives : This study examined the prevalence of psychiatric problems in children with scholastic difficulties who had been referred for mental health services from the Office of Education in Ulsan Metropolitan City.

Methods : Child psychiatrists evaluated the referred children using the DSM-IV. Evaluation tools included the Wechsler Intelligence Scale for Children-III, the Children's Depression Inventory, the Korean form of the State-trait anxiety Inventory for children, the ADHD rating.

Results : Seventy-six children consisting of 64 boys (84.2\%) and 12 girls (15.8\%) participated in the study. The average age was 10.3 ( $\mathrm{SD}=0.93$ ) years old. Approximately $74 \%$ of the children referred for scholastic difficulties were diagnosed with mental retardation. The Axis I diagnosis among these children were ADHD (86.8\%), depression (21.1\%), learning disorder (9.2\%), communication disorder (4.8\%), pervasive developmental disorder (3.6\%), internet addiction (1.3\%), and mood disorder (1.3\%). Their overall measure according to the Child Depression Inventory was $22.7(\mathrm{SD}=16.8)$, that for the State-Trait Anxiety Inventory for Children was $33.3(\mathrm{SD}=7.9) / 32.4(\mathrm{SD}=9.5)$, and that for the ADHD rating scale was 18.9 (SD=10.9).

Conclusion: These results suggest that many children with scholastic difficulties have both complex psychiatric and educational problems.

KEY WORDS : Mental Retardation · Learning Disorder - Depression · Anxiety.

\section{서 론}

학업성취에 어려움을 보이는 것은 학령기 아동들에게 큰 어려움을 주는 문제중의 하나이다. 1962년에 처음으로 사 용된 학습장애라는 용어는 넒은 의미로는 지적장애나 뇌손 상 혹은 정서적 문제를 포함한 어떠한 요인에 의해서건 학

접수완료:2010년 2월 1일 / 심사완료:2010년 4월 1일

Address for correspondence: Soo-Young Bhang, M.D., M.P.H., Department of Psychiatry, University of Ulsan, College of Medicine, Jeonha 1-dong, Dong-gu, Ulsan 682-714, Korea

Tel : +82.52-232-3309, Fax : +82.52-250-7070

E-mail : dresme@dreamwiz.com
습에 어려움을 보이는 경우를 모두 뜻한다. ${ }^{1)}$ 좁은 의미의 학 습장애는 미국정신의학편람(DSM-IV)의 정의를 따르면 '읽 기, 산술, 쓰기를 평가하기 위해 개별적으로 시행된 표준화 검사에서 나이, 학교 교육, 그리고 지능 등으로 기대되는 수 준보다 성적이 현저히 낮을 때’라고 정의된다. 또한 학업 실 패가 낮은 지능에 기인된 “학습지진”이나 우울, 불안과 같은 정서적 문제에 기인되어 학습에 어려움을 보이는 “학습부 진”이 있다. ${ }^{1}$ 학업 성취의 부진은 아동의 발달에 영향을 미 치는 생물학적, 심리적, 사회문화적, 교육적인 요인들의 영 향을 받는데 이들에게 적절한 치료를 제공하지 않고 방치하 는 경우 자존감 저하, 우울증 등 정서적인 문제가 동반될 수 있어, ${ }^{1)}$ 정신과 의사뿐만 아니라 임상 심리학자, 특수교육자 
등 다양한 분야의 전문가들이 긴밀한 협조를 통하여 학습 문제를 조기에 진단하고 아동에게 가장 적절한 개입을 해 주는 것이 중요하다.

학습장애를 가진 아동들이 전반적으로 자신감이 낮고 동 기가 부족하며, 좌절감, 실망감 등을 지속적으로 느끼고, 사 회적 접촉이 만족스럽지 못하며, 주어진 과제를 끝내지 못하 고 사람들 앞에 나서지 못하는 특성을 갖으며, 자아상이 저 하되고 불안과 우울이 증가하는 특징을 보인다. ${ }^{2}$ 국내의 한 연구에서는 학습장애를 가진 아동의 $44 \%$ 가 주의력결핍 과 잉행동장애(attention-deficit hyperactivity disorder, $\mathrm{ADHD}), 39 \%$ 가 우울증, $10 \%$ 에서 불안장애를 보였으며, 이 외에도 짜증이 많고 지나치게 예민하다는 반응 및 매사에 의욕과 관심이 없는 행동 특징 등을 보였다. ${ }^{3)}$ 학습장애를 가진 아동이 사춘기가 되었을 때 알코올 및 약물 남용의 위 험이 높아져 미국의 경우에는 약물 남용으로 치료를 받는 청소년의 $60 \%$ 가 학습장애에 해당되기도 하다. ${ }^{4)}$

2006년도 초 3 기초학력 진단평가 결과를 보면, 읽기 영역 에서의 미도달 학생의 비율은 $2.4 \%$, 쓰기 영역은 $2.0 \%$, 기 초 수학영역은 $4.4 \%$ 에 해당하였다. 미도달 학생들의 장애 요 인으로는 학생의 주의집중력 부족, 학생의 낮은 흥미, 부모 관심 및 지도 부족이 문제점으로 보고되고 있다. ${ }^{5)}$ 우리나라 에서는 특수학급 아동 혹은 학습장애 클리닉 내원 아동 대 상으로 이들의 임상적 특성 ${ }^{2,3,6)}$ 에 대한 기존의 보고는 있으 나, 특수학급에 배정 받거나 원인 평가를 받아 개별적으로 도움을 받지 않는 경우면서 기초학습부진이 지속되는 경우 에 대한 보고는 없는 상황이다. 따라서, 본 연구에서는 국 민공통과정 중에 있는 일반학급의 초등학생 중 기초학습부 진으로 의뢰된 학생들의 자료를 분석하여 아동의 심리, 정 신과적 평가 결과 및 부모의 특성을 보고하고자 한다.

\section{방 법}

\section{1. 대 상}

일 광역시 교육청에서는 2008년부터 기초학습부진학생 책임지도 지원팀 조직하고 기초학습부진학생으로 평가된 경 우 능력별, 영역별 맞춤식 지도를 실시하는 등 기초학습부 진학생에 대한 지원 활동을 하고 있다. 학년초 기초학습부 진학생으로 평가된 초등학교 3 6학년 학생에 대하여 2008 년 학년 말 기초학습부진학생 재평가를 실시하였으며, 평가 결과 구제되지 못한 학생이 350 명에 해당하였다. 이들의 기 초학습부진원인 파악 및 적절한 지도방안 마련을 위하여 8 시간 동안 '기초학력검사(Korean Institute of Special Education-Basic Academic Achievement Test, KISE-
BAAT)' 연수를 받은 담임 교사가 일대일로 학생을 평가하였 다. KISE-BAAT는 읽기, 쓰기, 기초수학의 기초능력을 평 가하는 검사로, 개인별로 60 90분이 소요되며 만 4세 14 세까지 아동을 대상으로 학력지수와 학년 규준을 산출할 수 있는 표준화된 검사로 신뢰도 및 타당도. ${ }^{78}$ 가 검증되어 있다. 대상자 중 KISE-BAAT결과 학력지수가 70 이하인 학생은 130 명이었고, 정신과 면담에 동의한 학생 및 보호자 는 94 명이었다.

\section{2. 방 법}

지역적 접근성을 고려하여 소아정신과 전문의가 근무하는 세 곳의 병원에서 분산하여 평가하였다.

\section{1) 개인력 및 발달력}

대상자들의 성별, 연령, 학년, 발달력 및 가정환경 즉 부모 연령 및 학력 수준, 평균 수입, 거주 형태, 가족 수, 1 차 양육 자, 출생 순위, 결혼 상태, 부모 직업 등이 조사되었다.

\section{2) 임상 진단 및 추적관찰}

소아정신과 진료실에서 아동 및 보호자와 개별적인 정신 과적 면담이 최소 2 회 이상 실시되었으며, 각 회당 최소 15 분 이상이 소요되었다. 진단명은 자료 수집시까지 기록된 의 무기록을 토대로 수집되었다. 추적관찰을 한 경우는 정신과 적 진단과 관련하여 약물 치료 및 정기적인 진료를 시작한 경우로 정의하였다.

\section{3) 아동용 웩슬러 개인지능검사(Korean-Wechsler Intelligence} Scale for Children-III, K-WISC-III)

임상에서 널리 사용되고 있는 $\mathrm{K}-\mathrm{WISC}-\mathrm{III}$ 는 곽금주 등 이 2001년에 표준화 ${ }^{9}$ 하였다. 3 개의 보충검사를 포함하여 총 13 개의 소검사로 되어 있으며 소검사들은 지능에 대한 서 로 다른 여러 가지 정신능력을 탐색하기 위하여 선정되었고, 언어성 지능과 동작성 지능, 그리고 총 지능 점수를 산출할 수 있으며 아동의 일반적인 지적 능력을 반영한다.

\section{4) 소아 우울척도(Children's Depression Inventory, CDI)}

소아의 우울 정도를 측정하기 위한 도구로, Beck의 우울 척도를 8 13세의 소아에 맞게 변형한 것이다. 모두 27문항 으로 구성되어 있으며 지난 2 주간의 기분상태를 자기보고로 평가하게 되어 있다. 문항마다 0 2점으로 총점의 분포는 0 54점 사이이다. 14.7점이 평균, 7.3점이 표준편차로 보고 되어 있다. ${ }^{10} 1998$ 년의 국내 연구 ${ }^{11}$ 에서는 평균 11.69 (표준편 차 7.29 8.39)로 보고되어 있다. 22 25점은 약간의 우울 상태, 26 28점은 상당한 우울상태, 29점 이상은 매우 심 한 우울상태로 볼 수 있다. 
5) 소아의 상태-특성불안척도(Korean form of the state-trait anxiety Inventory for children, STAIC)

상태 불안은 “현재 어떻게 느끼고 있는가?”를, 특성불안 은 “평소에 어떻게 느끼고 있는가?”를 아동이 스스로 답하 도록 되어 있다. 이 척도는 조수철 등리에 의하여 표준화된 척도로서 각 항목에 대하여 1 3점으로 평가하여 상태 불 안, 특성 불안 각각 0 60점 사이에 분포한다. 국내 연구 ${ }^{11)}$ 에 따르면 초등학교 5 6학년의 상태불안 척도의 전체 평균 점수는 남자 30.1(표준편차 7.8)점, 여자 33.0(표준편차 8.4) 점, 특성불안 척도 평균 점수는 남자 30.4(표준편차 6.9)점, 여자 32.7(표준편차 8.0)점으로 알려져 있다. 특성불안 척도 의 경우 39 42점이 '약간', 43 46점이 '상당히', 47 점 이상 이 '매우 높음에 해당한다. 상태불안 점수의 경우에는 41 44 점은 '약간', 45 48점은 '상당히', 49점 이상은 '매우 높음에 해당한다. ${ }^{6)}$

\section{6) 부모용 $\mathrm{ADHD}$ 평가 척도(ADHD Rating Scale, ARS)}

$\mathrm{ARS}$ 는 정신장애의 진단 및 통계 편람(DSM-IV)에 제시 된 진단 준거들에 기초한 행동 평가 설문지이다. 부주의성 을 시사하는 9 개의 문항과 과잉활동-충동성을 시사하는 9 개의 문항을 합하여 총 18 문항으로 구성되었다. 소유경13) 등 에 의하여 한국어로 번역되어 신뢰도와 타당도가 검증되었 고 지역사회 선별기준으로도 연구 ${ }^{14)}$ 되어 있다. 김영신 등히은 부모용 ARS에서 11세를 기준으로 하면 $90^{\text {th }}$ percentile이 부주의는 남아에서는 14 점, 여아에서는 12 점이었고, 과잉행 동-충동성은 남아에서는 11점, 여아에서는 9점이었으며, 총 점에서는 남아는 22 점, 여아는 20 점이었다.

\section{7) 한국아동인성평가척도(Korean Personality Inventory for Children, K-PIC)}

아동의 정서와 행동, 인지 등의 심리특성을 측정하는데 유용한 척도로서 우리나라에서는 김승태 등히이 번안하였 다. 4 개의 타당도 척도와, 자아탄력성 척도 및 11 개의 임상 척도로 구성되어 있으며, 예, 아니오로 답한다. 총 255 문항 으로 구성되며 임상척도로는 자아강도, 언어문제, 운동문 제, 불안, 우울, 신체화, 비행행동, 산만함, 가족갈등, 사회위 축, 정신증상, 자폐증상으로 이루어져있다.

\section{8) 주의력 장애 진단 시스템 (ADHD Diagnostic system, ADS)}

$\mathrm{ADS}$ 는 컴퓨터로 검사하는 연속수행검사이다. 1999년에 홍강의 등기 에 의하여 개발되고 표준화되었다. 시각검사와 청각검사로 나누어져있고 초등학생의 경우 각각 15 분이 소 요된다. 전반적인 주의력을 평가할 수 있으며, 세부적인 평가 지표로는 누락오류, 오경보오류, 정반응시간의 평균, 정반응
시간의 표준편차, 민감도, 반응기준 등이다. 누락오류, 오경 보오류, 정반응시간의 표준편차 상에서 기준점수(버전 1.0에 서는 70 점, 버전 2.0 에서는 65 점) 이상의 점수가 나타나는 경우에는 주의력결핍-과잉행동장애를 의심해 볼 수 있다. 본 연구를 시행한 병원 중 두 곳은 $\mathrm{ADS} 1.0$ 을 사용하였고 한 곳은 ADS 2.0 을 사용하였다.

\section{9) 반항성 장애 및 따돌림 척도}

반항성 장애 및 따돌림 경험에 대한 설문을 실시하였다. 한국 임상 심리학회에서 제작한 반항성 장애 척도와 학교 따돌림 척도를 사용하였다. ${ }^{18)}$ 반항성 장애 척도의 경우 각 문항에 대해 4 가지 정도로 평정 하고, 표시된 각 정도의 합 계를 기록하는데, '상당히,' '아주 심함에 표시된 수를 합하여 총합계를 구하게 된다. 반항성장애 척도의 경우 8 개 문항 중 1 개 이하는 보통 수준, $2 \sim 3$ 개는 다소 반항적인 수준, 4 개 이 상은 반항성 장애의 가능성에 해당한다. 학교 따돌림 척도는 12 개 문항 중 2 개 문항 이하에 해당하는 경우 일시적 따돌림 일 가능성 많음, 3 7개는 학교에서 따돌림 받을 가능성 있 음, 8 개 이상의 경우 돌림 받을 가능성 매우 높음으로 해석 하는 것으로 제시되고 있다.

\section{0) 다면적 인성검사(Minnesota Multiphasic Personality Inventory, MMPI)}

$\mathrm{MMPI}$ 는 전 세계적으로 널리 쓰이고 가장 많이 연구된 성격검사이다. 1940 년 제작된 MMPI는 정신병리의 진단 분 류라는 초기 목적을 넘어 성격검사로서 광범위하게 사용되어 왔다. ${ }^{19)}$ 임상척도로는 건강염려증 $(\mathrm{Hs})$, 우울증(D), 히스테리 $(\mathrm{Hy})$, 반사회성 $(\mathrm{Pd})$, 남성성-여성성 $(\mathrm{Mf})$, 편집증 $(\mathrm{Pa})$, 강박증 $(\mathrm{Pt})$, 정신분열증 $(\mathrm{Sc})$, 경조증 $(\mathrm{Ma})$, 내향성 $(\mathrm{Si})$ 가 있다. 성인 용 MMPI-2를 사용하여 부모의 성격을 평가하였다.

\section{3. 통계분석}

광역시 내의 소아정신과 전문의가 있는 3 곳의 병, 의원에 서 심리평가 자료 및 진단과 관련한 자료를 취합하여 분석하 였으며 본 연구는 울산대학교병원 임상연구윤리위원회(IRB) 의 승인을 받았다. 유의수준 $95 \%$ 로 p value .05 미만을 유의 한 것으로 하여 분석하였고, 평균의 비교는 $\mathrm{T}$ 검정과 $\mathrm{ANO}$ $\mathrm{VA}$, 상관분석은 피어슨 상관분석, 군집분석은 $\mathrm{K}$ 평균 군집분 석을 사용하였다. 통계 프로그램은 SPSS 17.0을 사용하였다.

\section{결 과}

정신과 면담에 동의한 94 명 중 내원한 학생은 76 명이었으 며, 내원하지 않은 학생(18명)의 성비 및 연령, 학력지수의 
차이는 없었다. 남학생은 64 명(84.2\%), 여학생은 12 명(15.8\%) 으로, 의뢰된 학생은 남학생이 많았다. 현 연령은 9 12세로 평균 10.3(SD=0.93)세였다. 대상군의 일반적인 특성을 Table 1 에 나타내었다. 출생시 모의 평균 연령은 $29.9(\mathrm{SD}=4.5)$ 세 였 으며, 4 명의 학생은 임신 중에 모의 약물 복용력이 확인되었 다. 출생 시 저 체중이었던 경우는 4 명 $(7.4 \%)$, 발달지연을 보 고한 경우는 18 명(31\%), 임신 중 음주나 흡연을 한 경우는 각 각 8명(13.4\%), 1 명(1.7\%)이었다. 15 명(27.3\%)에서 경련을 한 적이 있었다. 부의 평균 연령은 $44.7(\mathrm{SD}=4.7)$ 세 였으며 모의 평균 연령은 $40.7(\mathrm{SD}=5.4)$ 세였다. 부모의 학력이 고졸 이하인 경우는 부는 9 명 $(11.8 \%)$, 모는 6 명 $(7.9 \%)$ 였다. 부모의 결혼 상 태를 확인할 수 있었던 자료 $(\mathrm{n}=58)$ 중에서 47 명(81.0\%)은 결 혼상태였고, 2 명(3.4\%)은 별거, 3 명(5.2\%)은 이혼, 6 명(10.3\%) 은 기타였다. 가구의 한달 수입이 100 만원 미만인 경우가 12 명(21.4\%)이었다.

\section{1) 임상 진단(Table 2)}

소아정신과 전문의의 임상적 면담에 의하여 진단하였다. DSM-IV의 I축 진단에 해당하는 학생이 76명 중 67명(88\%) 에 해당하였으며, 67 명 중 2 가지 이상의 진단을 지닌 경우는 30 명(45\%)에 해당하였다. I축 진단으로는 $\mathrm{ADHD}$ 가 66 명 (86.8\%), 우울증 16 명(21.1\%), 학습장애 7 명 $(9.2 \%)$, 의사소통 장애 3 명 $(4.8 \%)$, 발달장애 2 명 $(2.6 \%)$, 인터넷 중독 1명(1.3\%), 기분장애 1 명(1.3\%), 말더듬 1명(1.3\%)이었다. 또한 DSM-IV의 II축 진단으로는 지적장애가 56명(73.7\%)이었다. 면담 이후 약물 치료 등 정신과적 개입을 시작한 경우는 36 명(47.4\%)이 었다.

\section{2) 지능 및 주의력 검사 결과(Table 3)}

전체지능의 분포는 34 95점으로 평균 62 점 $(\mathrm{SD}=14.5)$ 이 었고 남녀의 차이는 없었다. 지능지수 85이상인 아동이 7명 (9.3\%), 경계성 지능(지능지수 71 84)인 아동이 14명(18.7\%), 경도 정신지체(지능지수 50 70)가 42명(55.3\%), 중등도 혹 은 중증(지능지수 50 미만)이 12 명(15.8\%)에 해당하였다.

부모용 $\mathrm{ADHD}$ 평가 척도의 경우 평균 점수는 $18.9(\mathrm{SD}=10.9$, $\mathrm{n}=74)$ 점 이었으며, 20 점 이상에 해당하는 아동은 34 명 $(46 \%)$ 였 다. $\mathrm{ADHD}$ 진단 시스템(ADS) 점수는 연령과 성별을 고려하여 표준점수를 산출하므로 이를 사용하여 분석하였다. 시각주의 력검사에서 누락오류는 평균 87.2(SD=55.1), 오경보오류는 평 균 68.4(SD=20.7), 정반응시간의 표준편차는 $89.4(\mathrm{SD}=38.5)$ 였 고, 청각주의력검사에서는 누락오류는 평균 89.1(SD=29.1), 오 경보오류는 평균 $84.1(\mathrm{SD}=31.0)$, 정반응시간의 표준편차는 $75.8(\mathrm{SD}=22.2)$ 에 해당하였다. $\mathrm{ADS}$ 버전 1.0을 기준으로 총 6 개의 변수에서 모두 70점 이하인 정상 범주에 해당하는 학생은
3 명(3.9\%)에 불과하였다. 또한, 1 개 변수가 70 점 이상인 경우는 10 명(13.2\%), 2 개의 변수가 70 점 이상인 경우는 13 명(17.1\%), 3 개 의 변수가 70 점 이상인 경우는 12 명( $15.8 \%), 4$ 개의 변수가 70 점 이상인 경우는 15 명(19.7\%), 5 개 이상 변수가 70 점 이상인 아동은 18 명 $(23.4 \%)$ 이었다.

\section{3) 우울, 불안, 반항성 장애, 따돌림 척도 점수}

소아우울척도의 평균은 22.7점( $\mathrm{SD}=16.8)$ 이었으며, 소아 특성불안척도의 평균은 33.3점( $\mathrm{SD}=7.9)$, 소아 상태불안척도 의 평균은 32.4 점 $(\mathrm{SD}=9.5)$ 이었다. 소아우울척도를 제출한 66 명에서 22점 이상인 학생은 21명(31.8\%)였는데, 약간의 우 울상태(22 25점)는 4명(6.1\%), 상당한 우울상태(26 28점) 는 8명(12.1\%), 매우 심한 우울상태(29점 이상)는 9명(13.6\%)

Table 1. Demographic variables of the participants $(n=76)$

\begin{tabular}{|c|c|c|}
\hline Variables & & $N(\%)$ or Mean (SD) \\
\hline \multirow[t]{2}{*}{ Gender } & Male & $64(84.2)$ \\
\hline & Female & $12(15.8)$ \\
\hline \multirow[t]{3}{*}{ Academic years } & $4^{\text {th }}$ & $28(36.8)$ \\
\hline & $5^{\text {th }}$ & $27(35.5)$ \\
\hline & $6^{\text {th }}$ & $21(27.6)$ \\
\hline $\begin{array}{l}\text { History of developmental } \\
\text { delay }(n=58)\end{array}$ & & $18(31.0)$ \\
\hline History of seizure $(n=55)$ & & $15(27.3)$ \\
\hline \multirow[t]{2}{*}{ Parent's age } & Father & $44.7(4.7)$ \\
\hline & Mother & $40.7(5.4)$ \\
\hline \multirow{2}{*}{$\begin{array}{l}\text { Parent's education below } \\
\text { high school }\end{array}$} & Father & $9(11.8)$ \\
\hline & Mother & $6(7.9)$ \\
\hline \multirow[t]{4}{*}{ Marital status (n=58) } & Married & $47(81.0)$ \\
\hline & Separated & $2(3.4)$ \\
\hline & Divorced & $3(5.2)$ \\
\hline & Other & $6(10.3)$ \\
\hline \multirow[t]{3}{*}{ SES (income) $(n=56)$} & $<1,000 \$ /$ month & $12(21.4)$ \\
\hline & $\begin{array}{l}1,000-3,000 \\
\$ / \text { month }\end{array}$ & $28(50)$ \\
\hline & $>3,000 \$ /$ month & $16(28.6)$ \\
\hline
\end{tabular}

Table 2. Clinical diagnosis of the participants

\begin{tabular}{llr}
\hline & \multicolumn{1}{c}{ Diagnosis } & $\mathrm{N}(\%)$ \\
\hline Axis I & ADHD & $66(86.8)$ \\
& Depression & $16(21.1)$ \\
& Learning disorder & $7(9.2)$ \\
& Communication disorder & $3(4.8)$ \\
& Pervasive developmental disorder & $2(2.6)$ \\
& Mood disorder & $1(1.3)$ \\
& Stuttering & $1(1.3)$ \\
& Internet addiction & $1(1.3)$ \\
Axis II & Mental retardation & $56(73.7)$ \\
\hline
\end{tabular}

ADHD : attention-deficit hyperactivity disorder 
에 해당하였다. 특성불안 척도를 제출한 72 명중 39 점 이상 인 학생은 18 명(23.6\%)였는데, 약간의 특성불안(39 42점) 은 10명(13.8\%), 상당히(43 46점)는 4명(5.6\%), 매우 높음 (47점 이상)은 4 명(4.2\%)이었다. 상태불안 점수를 제출한 70 명중 41점 이상인 학생은 13 명(17.5\%)였는데, 약간의 특성불 안(41 44점)은 6명(8.6\%), 상당히(45 48점)는 5명(6.5\%), 매우 높음(49점 이상)은 2 명(2.9\%)이었다. 부모가 평가한 반 항성장애 척도 $(n=46)$ 의 경우 다소 반항적인 수준은 8 명 (16\%), 반항성 장애의 가능성이 있는 경우는 18명(23.7\%)에 해당하였다. 학교 따돌림 척도를 제출한 학생 $(\mathrm{n}=50)$ 중 학교 에서 따돌림 받을 가능성 있는 군은 19 명(38\%)였고, 가능성 이 매우 높은 군은 3명(3.9\%)이었다. 따돌림 척도 점수와 우 울증 척도 점수 $(r=0.392, \mathrm{p}=.005, \mathrm{df}=44)$ 및 특성불안 척도 점수 $(\mathrm{r}=0.490, \mathrm{p}<.001, \mathrm{df}=44)$ 는 유의한 상관를 보였으며, $\mathrm{K}-\mathrm{PIC}$ 의 언어 $(\mathrm{r}=0.396, \mathrm{p}=.008, \mathrm{df}=44)$, 운동 $(\mathrm{r}=0.589, \mathrm{p}$ $<.001, \mathrm{df}=44)$, 우울 $(\mathrm{r}=0.350, \mathrm{p}=.020, \mathrm{df}=44)$, 과잉행동 $(\mathrm{r}=0.397, \mathrm{p}=.008, \mathrm{df}=44)$, 정신증 $(\mathrm{r}=0.367, \mathrm{p}=.014, \mathrm{df}=$
44), 자폐증 $(\mathrm{r}=0.477, \mathrm{p}=.001, \mathrm{df}=44)$ 척도에서 유의한 양 의 상관을 보였다.

\section{4) 한국 아동 인성 검사(Table 3, Fig. 1)}

$\mathrm{K}-\mathrm{PIC}$ 의 평균 점수를 Table 3 에 기술하였다. $\mathrm{K}-\mathrm{PIC}$ 평 균 점수는 언어 $(\mathrm{p}<.001,95 \% \mathrm{CI}: 8.6 \sim 15.3, \mathrm{df}=69)$, 운동 $(\mathrm{p}<.001,95 \% \mathrm{CI}: 7.9 \sim 14.6, \mathrm{df}=69)$, 불안 $(\mathrm{p}=.015,95 \% \mathrm{CI}$ : $0.7 \sim 6.2, \mathrm{df}=69)$ 우울 $(\mathrm{p}<.001,95 \% \mathrm{CI}: 5.5 \sim 10.5, \mathrm{df}=6.9)$, 과잉행동 $(\mathrm{p}<.001,95 \% \mathrm{CI}: 5.8 \sim 11.8, \mathrm{df}=69)$, 사회관계 $(\mathrm{p}<$ $.001,95 \% \mathrm{CI}: 5.8 \sim 10.3, \mathrm{df}=69)$, 자폐증 $(\mathrm{p}<.001,95 \% \mathrm{CI}$ : 6.8 16.3, $\mathrm{df}=48$ ) 척도에서 표준 집단에 비하여 유의한 차 이를 보였다.

$\mathrm{K}-\mathrm{PIC}$ 의 유의한 차이가 전반적인 아동의 문제인지 특정 군에 해당하는 문제가 두드러지는 지 확인하기 위하여 $\mathrm{K}-$ $\mathrm{PIC}$ 척도 점수 중 누락된 자료가 많았던 자폐증을 제외하고 $\mathrm{K}$ 평균 군집분석을 한 결과 2 개의 군집으로 구분되었다. Group 1(n=37, 53\%)은 언어문제를 제외하고는 정상범주인 아동들이었고 Group 2(n=33, $47 \%)$ 는 언어문제를 포함한

Table 3. Results of Psychological tests

\begin{tabular}{|c|c|c|c|c|c|}
\hline & & Mean & SD & Clinical population (n)* & Clinical population (\%) \\
\hline \multirow[t]{3}{*}{ K-WISC-III } & Total IQ & 62.0 & 14.5 & 56 & $73.7 \%$ \\
\hline & Verbal IQ & 63.9 & 14.1 & & \\
\hline & Performance IQ & 67.4 & 16.4 & & \\
\hline \multirow[t]{4}{*}{ ADS -visual } & Omission & 87.7 & 55.3 & 31 & $40.8 \%$ \\
\hline & Commission & 68.4 & 20.7 & 25 & $34.7 \%$ \\
\hline & Reaction time & 58.9 & 13.7 & & \\
\hline & Reaction time SD & 89.4 & 38.5 & 43 & $59.7 \%$ \\
\hline \multirow[t]{4}{*}{ ADS-auditory } & Omission & 88.1 & 29.1 & 46 & $64.8 \%$ \\
\hline & Commission & 84.1 & 31.0 & 43 & $60.6 \%$ \\
\hline & Reaction time & 50.4 & 22.2 & & \\
\hline & Reaction time SD & 75.8 & 22.2 & 45 & $63 . \%$ \\
\hline CDI score & & 22.7 & 16.8 & 21 & $31.8 \%$ \\
\hline TAIC score & & 33.3 & 7.9 & 18 & $23.6 \%$ \\
\hline SAIC score & & 32.3 & 9.5 & 13 & $17.5 \%$ \\
\hline \multirow[t]{11}{*}{ K-PIC score } & VDL & 71.7 & 14.3 & & \\
\hline & PDL & 61.2 & 14.1 & & \\
\hline & ANX & 53.4 & 11.5 & & \\
\hline & DEP & 58.0 & 10.4 & & \\
\hline & SOM & 49.8 & 10.3 & & \\
\hline & DLQ & 52.0 & 12.7 & & \\
\hline & HPR & 58.8 & 12.5 & & \\
\hline & FAM & 53.3 & 15.1 & & \\
\hline & SOC & 58.1 & 9.5 & & \\
\hline & PSY & 51.5 & 18.1 & & \\
\hline & AUT & 61.5 & 16.5 & & \\
\hline
\end{tabular}

* : Clinical population: Total IQ $\leq 70$; ADS T score $\geq 70$, CDI score $\geq 22$, TAIC score $\geq 39$, SAIC score $\geq 41$. K-PICSD : Standard deviation, K-WISC-III : Korean-Wechsler Intelligence Scale for Children-III, ADS : ADHD Diagnostic system, CDI : Kovac's children's depression inventory, TAIC : Spielberger Trait Anxiety Inventory, SAIC : Spielberger State Anxiety Inventory 
전반적인 행동, 정서상의 문제를 지닌 군이었다. 이들 두 군 의 $\mathrm{K}-\mathrm{PIC}$ 소 척도간 점수 차이는 그룹간 $\mathrm{t}$ 검정에서 모든 소 척도에서 유의하였다(Fig. 1). Group 2의 경우, 지능검사의 동 작성 지능의 평균의 차이가 8.0점 $(\mathrm{SD}=3.9,95 \% \mathrm{CI}: 0.2 \sim$ $15.8)$, 상식 소검사의 평균의 차이가 1.2 점 $(\mathrm{SD}=0.5,95 \% \mathrm{CI}$ : 0.8 2.2), 기호 소검사의 평균의 차이가 1.3 점 $(\mathrm{SD}=0.5,95 \%$ CI: 0.3 2.2)으로 Group 1 보다 낮은 수행을 보였다. 또한, 모 의 $\mathrm{MMPI}$ 에서 우울증 $(\mathrm{D})$, 반사회성 $(\mathrm{Pd})$, 편집증 $(\mathrm{Pd})$, 강박증 $(\mathrm{Pt})$, 정신분열증 $(\mathrm{Sc})$ 가 Group 2 가 Group 1에 비하여 유의한 차이를 보였다.

\section{5) 부모의 MMPI-2의 특징(Fig. 2)}

부모의 MMPI- 2 를 실시하였는데, 모 $(\mathrm{n}=41)$ 의 경우, 정 신분열증 척도 $(\mathrm{Sc})$ 가 평균 $46.7(\mathrm{SD}=10.0)$ 로, 규준 집단과 비교하여 평균 3.3점 낮았고 $(95 \% \mathrm{CI}:-6.5 \sim-0.2, \mathrm{p}=.004$, $\mathrm{df}=40)$, 부 $(\mathrm{n}=38)$ 의 경우, 남성성-여성성 $(\mathrm{Mf})$ 척도가 평균 46.2( $\mathrm{SD}=9.2)$ 로, 규준 집단과 비교하여 평균 3.8점 낮았으 나 $(95 \% \mathrm{CI}:-6.8 \sim-0.7, \mathrm{p}=00.2, \mathrm{df}=37)$, 다른 점수들의 평균은 규준집단과 평균의 차이는 없었다. 그러나, 부모의 MMPI-2에 대하여 군집분석을 실시하여 군을 분류하여 보 면, 전반적인 프로파일이 상승되어 있는 군집이 구분되었 다. 부의 경우 MMPI-2 자료가 분석된 총 35 명 중, 문제가 있는 군(Group 2)이 11명(31\%), 그렇지 않은 군(Group 1)이 24 명 $(69 \%)$ 에 해당하였다. 모의 경우 총 41 명 중 문제가 있 는 군(Group 2)이 10명(24\%), 그렇지 않은 군(Group 1)이 31 명 $(76 \%)$ 에 해당하였다. 모의 남성성-여성성 척도 $(\mathrm{Mf})$ 와 경조증 척도 $(\mathrm{Ma})$, 부의 경조증 척도 $(\mathrm{Ma})$ 를 제외한 모든 척 도에서 군간 통계적으로 유의한 차이를 보였다. 모가 Group 2 에 해당하는 경우 아동의 KISE-BAAT에서 쓰기 점수가 평균 9.3( $\mathrm{SD}=4.5)$ 점 낮아 유의한 차이 $(\mathrm{p}=.046,95 \% \mathrm{CI}$ : $-18.5 \sim-0.15, \mathrm{df}=39)$ 를 보였고, $\mathrm{K}-\mathrm{PIC}$ 의 가족관계 점수 가 $5.2(\mathrm{SD}=3.2)$ 점 높아 유의한 차이 $(\mathrm{p}=.001,95 \% \mathrm{CI}: 6.7 \sim$ $22.5, \mathrm{df}=38$ )를 보였다. 부의 MMPI 그룹간 아동의 특성의 차이는 없었다.

\section{고 찰}

학습장애의 진단에 있어 능력(지능)과 성취의 불일치 모델 이외에 중재-반응 접근법이 있다. 이는 효과적인 수업에 얼 마나 반응하는가 하는 정도로 학습장애 여부를 판단하는 접 근으로, 1995년 Fuchs 등이 조작적으로 정의한 이래 2000 년도 초기부터 미국에서 많은 지지를 받고 있으며, ${ }^{20)} 2007$ 년부터 미국 장애인교육법에서는 심각한 불일치 모형 외에

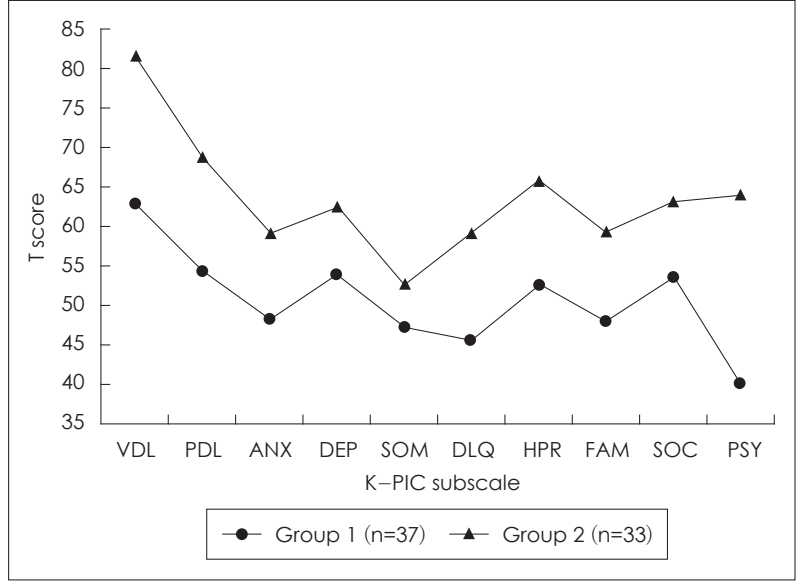

Fig. 1. Cluster analysis of participants' K-PIC Subscale

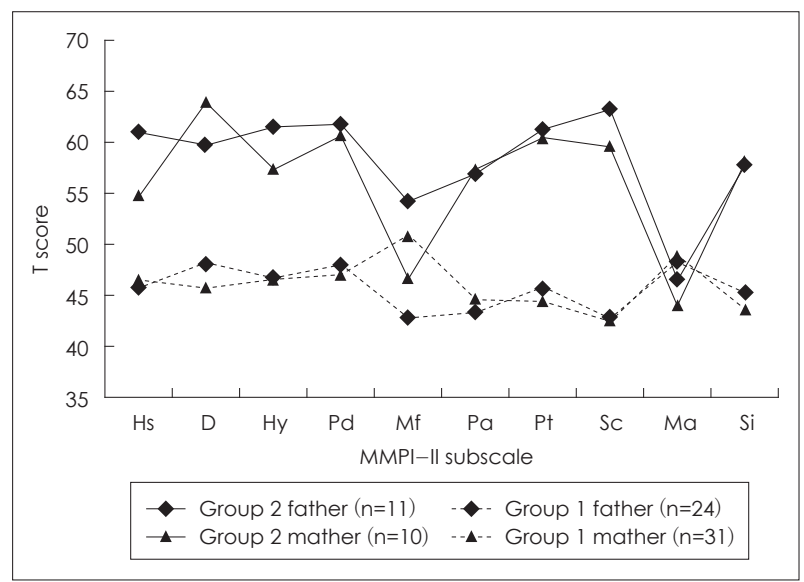

Fig. 2. Cluster analysis of parents' MMPI-2 scales

중재반응과정도 고려할 수 있도록 하였다. ${ }^{21)}$ 본 연구 대상자 들에게 제공 된 절차들은 이러한 중재-반응 접근법을 따르 고 있는 것으로 생각된다. 즉, 초등학생을 대상으로 학년 초 에 기초학력 미달인 경우를 선별한 다음, 필요한 교육을 제 공하고, 학년말에 재검사를 통해 학생들이 교육에 적절하게 반응하였는지를 점검하였다. 그리고 구제되지 못 한 학생에 대하여는 교사의 일대일 KISE-BAAT 평가를 통해 유의하 게 점수가 낮은 학생에 대하여 정신과적 문제에 대한 평가 를 실시하도록 하였다. 이 연구는 이러한 중재 반응 모델의 마지막 단계로 볼 수 있는 개별적이고 종합적인 정신과적 평 가를 시행한 결과를 보고한 첫 연구이다.

대상자의 특징을 보면, 일 광역시의 교육청에서 기초학력 미달로 의뢰된 학생의 $84.2 \%$ 가 남학생이었다. $74.7 \%$ 가 지 적장애에 해당하여, DSM-IV-TR의 II축 진단에 해당하였 다. I축 진단의 경우, $\mathrm{ADHD}(86.8 \%)$, 우울증(21.1\%), 학습장 애(9.2\%), 의사소통장애(4.8\%), 발달장애(2.6\%), 인터넷 중 독(1.3\%), 기분장애(1.3\%), 말더듬(1.3\%)으로 파악되었으며 공존진단률은 $45 \%$ 였다. 또한, $46 \%$ 의 아동이 ARS 20 점 이 
상으로 보고되었다. $\mathrm{ADS}$ 검사상 주의 집중력의 문제가 시 사되지 않는 아동은 $3.9 \%$ 에 불과하였다.

남학생의 비율이 높은 것은 특수학급에 아동의 임상 진단 을 보고한 임명호 등의 연구 ${ }^{6}$ 와 유사한데, 학습부진을 보이 는 여학생이 문제행동의 소지가 적어 의뢰에 누락되었을 가 능성도 있으나, 읽기 장애의 경우 남학생이 더 심한 양상을 보이고, ${ }^{1)}$ 대부분의 대상자가 지적장애에 해당되었으므로, 지 적장애의 유병률이 남자에서 1.6 배 ${ }^{22)}$ 정도 더 높은 점을 감안 할 때 남학생이 더 높은 비율로 의뢰되었을 가능성도 있을 것으로 보인다.

본 연구에서는 학습장애가 $9.2 \%$, 지적장애가 $74.7 \%$ 에 해 당하였는데, 이는 특수학급 아동을 보고한 다른 연구 들이 학습장애가 34 62\%, 지적장애가 28 31\% )ㅡㄹ 보고한 것이 나, 종합병원 학습장애 특수 클리닉에 내원한 아동의 경우 에 학습장애가 $20.8 \%$, 지적장애는 $15.7 \%$ 에 보고 ${ }^{3)}$ 되고 있는 것에 비하여 학습장애의 비율은 낮고, 정신지체의 비율은 매 우 높은 수준으로 나타났다. 학습장애의 비율이 낮은 것은, 연구 대상자의 대다수가 지적장애에 해당하여 임상의사가 '읽기 장애', '쓰기 장애', '산술 장애'와 같은 특정 학습장애가 지능에 의한 것이 아닐 때 학습장애를 진단하도록 되어있는 $\mathrm{DSM}-\mathrm{IV}$ 의 진단기준의 의하여 엄격하게 학습장애를 진단 하였기 때문에 학습장애의 비율이 높지 않은 것으로 보인 다. 또한 지적장애로 인하여 다각적인 지도에도 반응하지 않 는 학생이 의뢰되었을 선택편견의 가능성도 고려하여야 할 것으로 보인다.

대다수가 심각한 정신의학적 문제가 있음에도, 교육청의 지원으로 병, 의원을 찾게 된 아동의 부모는 정신의학적 서 비스의 필요성에 대하여 인지하지 못하고 있던 중 학습부진 의 원인을 찾고자 방문한 경우가 대다수였는데, 면담시 중 등도 지적장애의 경우에서도 평가 결과에 대하여 부정하는 경우도 존재하였다. 한편, 중등도 혹은 중증 지적장애가 대 상자의 $15.8 \%$ 에 해당하였는데, 이들은 또래에게 수행능력 에 있어 부정적으로 평가되어, 통합 교육에 적절하지 않을 수 도 있어() 이들에 대한 적절한 교육적 서비스가 더욱 시 급한 것으로 보인다. 대상자의 $55.3 \%$ 에 해당하는 경도 지 적장애의 경우 사회경제적 원인이 중요할 수 있는데, 환경적 인 원인으로는 가족내의 불안정성, 잦은 이사, 부적절한 보 살핌, 적절한 자극의 부족, 절대 빈곤층 혹은 사회경제적으 로 낮고 불우한 계층에서 교육과 경험 부족, 아동 학대 및 방임, 부모의 정신병리 등이이다. 본 연구에서는 모의 MMPI 프로파일이 전반적으로 상승한 경우, 아동의 쓰기 점수, 가 족 관계에 부정적인 영향을 미쳤다. 임상 면담시 필요한 경 우 아동에 대하여 특수교육 프로그램을 권하였고, 개별적인
가족교육을 실시하였으나, 지속적인 상담 또는 가족치료 통 하여 부모에게 도움을 주고, 대상 아동의 적응기술 및 사회 성 증진, 직업 훈련 등의 지속적이고 포괄적인 프로그램이 필요할 것으로 판단된다.

본 연구 대상자의 주의력결핍과잉행동장애(ADHD)의 비 율은 유병률인 2 4\% ${ }^{11}$ 나, 특수학급 대상의 선행연구에서의 $24.5 \%$, 종합병원 학습장애 특수 클리닉 내원 아동의 유병 률 $44 \%^{3}$ 에 비교하면 $86.8 \%$ 로 매우 높은데, $\mathrm{ADHD}$ 가 기초 학력미달에 영향을 주었을 가능성과 함께, 학습장애나 지적 장애와 $\mathrm{ADHD}$ 가 공존율이 높은 것에 기인한다고 생각할 수 있다. 주의집중력의 문제가 있는 경우 미국 국립 정신 보 건원의 다년간 연구된 연구조삼에 따르면 주의력결핍-과잉 행동장애는 약물치료에 의하여 $2 / 3$ 이상에서 치료적 도움을 받을 수 있으며, 인지 행동치료를 병행한 경우에는 80 90\% 의 치료적 개선을 보일 수 있다. 본 연구에서 면담 이후 정신 과적인 추적관찰을 하면서 약물 치료를 시작한 경우가 $47.4 \%$ 에 해당하여 이들의 의학적 치료가 학습부진 혹은 적 응 능력의 개선에 도움을 줄 수 있을 것으로 보인다.

일반 아동의 우울장애의 유병률은 $0.4 \sim 59 \%$ 까지 보고 ${ }^{1)}$ 되고 있는데, 국내에서 특수학급을 대상으로 하는 선행 연 구 $^{6}$ 에서는 우울장애가 $5.7 \%$, 불안장애가 $5.7 \%$ 로 보고된바 있다. 그러나, 종합병원 학습장애 특수 클리닉 내원 아동의 경우 우울증 등의 정서장애가 $33 \%$ 에 해당 ${ }^{3)}$ 하여 높은 비율 을 보였는데, 본 연구에서도 대상자 중 임상적 우울증으로 진단할 수 있는 아동이 $21.1 \%$ 에 해당하였고, 우울척도 점수 상 기준점 이상인 학생이 $31.8 \%$ 에 해당하였으며, 특성불안 과 상태불안 점수가 기준점 이상인 학생이 $23.6 \%, 17.5 \%$ 에 해당하였다. 본 연구의 대상 아동들의 아동인성검사에서도 불안, 우울 척도가 유의하게 상승되어 있었다. 이는 학습장 애를 가진 초등학교 남학생의 경우 자신감이 저하되어 있고 우울과 불안의 정도가 증가되어 있다는 국내의 보골ㅇㅇㅘ 일 치한다. 특수학급에서 학습하는 학생에 비하여 일반학급에 서 기초학습부진을 보이는 경우 우울증의 유병률이 더 높은 것은 본 연구 대상자들이 일반학급의 국민공통교육과정에 속해 있으나 대다수가 지적장애에 해당하여 능력에 비하여 과도한 스트레스를 경험할 수 있었을 것으로 보인다. 일반학 급 학생 중 학습문제를 가진 아동들의 경우, 인지적인 문제 외에도 정서적인 문제도 항상 함께 다루어야 할 것으로 보인 다. 적응문제에 있어서는 반항성 장애 척도상 대상자의 $39.7 \%$ 이 기준점 이상이었으며, 따돌림 가능성이 시사되는 학 생이 $41.9 \%$ 이나 되었고, 한국 아동 인성 검사에서도 사회성, 자폐증 척도의 유의한 상승이 있었는데, 이는 대인관계문제 와 행동문제가 학습장애아동에서 동반될 수 있으며 아동의 
자아상에 영향을 미친다는 선행연구 ${ }^{2}$ 와 유사한 결과라 할 수 있다. 본 연구에서도 따돌림 점수와 언어, 운동, 우울, 과 잉행동, 정신증, 자폐증 점수의 유의한 양의 상관을 보여, 아 동의 전반적인 정서, 행동, 사회성의 문제와 따돌림의 문제가 서로 관련이 있었다.

대상학생을 $\mathrm{K}-\mathrm{PIC}$ 의 전반적인 프로파일로 나누어 보면 $47 \%$ 학생이 $\mathrm{K}-\mathrm{PIC}$ 전반적인 프로파일이 상승하는 군집에 속하였다. 전반적인 프로파일이 상승되어 있는 군은 지능검사 에서 동작성 지능 및 상식과 기호 소 검사의 평균이 낮았으며, 이들의 모의 MMPI의 우울증, 반사회성, 편집증, 강박증, 정 신분열증 소척도가 유의한 차이를 보였다. 이와 같이 기초학 력 미달 학생들은 교육적인 문제 외에도 정서적인 어려움과 함께 사회성과 전반적인 행동문제가 공존하는 아동들이 상 당수 존재한다는 것을 알 수 있었다. 또한, 기초학습부진으 로 의뢰된 아동들의 부모의 $\mathrm{MMPI}$ 를 군집 분석한 결과에 서도 24 31\%의 부모가 MMPI 프로파일의 전반적인 상승 을 보였으며, 특히 모의 MMPI 프로파일이 상승된 경우에 는 아동의 쓰기 능력 및 가족관계에 부정적인 영향을 주는 것으로 분석되었다. 따라서, 기초학습부진인 아동의 경우 양 육자의 문제가 존재하는 경우가 다수 있고 아동의 학습에 영향을 줄 수 있는 바, 이에 대한 다각적인 접근이 필요한 학 생이 있을 것으로 생각된다.

학생의 사회적 배경과 상관없이 모든 학생이 교육적 성과 를 얻을 수 있도록 하는 것이 세계적인 추세로, 미국에서는 “뒤쳐지는 학생이 없게(No Child Left Behind, NCLB)" 법 안을 만들어 교육력 제고에 힘쓰고 있고, 영국도 교육과정의 개정을 통해 지식기반사회에서 필요한 기초 능력(Key Skill) 의 배양을 강조하고 있다. ${ }^{5)}$ 우리나라도 2001년 '국가 인적자 원 개발 기본계획'에 의거, 기초 교육을 충실하게 하여 학습 부진의 누적을 막는 국민 기초 교육 보장 정책을 추진하였 다. 이에 따라, 2002년부터 기초학력의 도달 여부를 파악하 고 기초학력 미도달자에게 보정교육 프로그램을 제공하여 학습결손의 누적을 최소화 하기 위하여 기초학력 진단평가 를 시행하고 있다. 2008년부터는 대한민국 초등학교 3학년 전수를 대상으로 읽기, 쓰기, 기초 수학 영역에 대하여 기초 학력 진단평가가 시행되고 있다. 또한 각 학년별 교육과정에 서 요구하는 최저 수준의 기본 학습능력을 진단하는 평가 인 교과학습 진단평가가 초 3 6학년에서 학년초에 시행되 고 있다. 이와 같은 평가를 통하여 교사와 학생이 기초학력 도달을 목표로 교육적인 개입을 실시하는데도 문제가 지속 되는 경우 정신병리와 같은 문제가 공존하는 지에 대한 평 가가 필요할 것 ${ }^{21}$ 으로 여겨지고 있다.

따라서, 이 연구의 장점은 일 광역시의 일선 학교에서 교
육적 중재에도 반응하지 않는 기초학습부진 아동을 의뢰 받아, 소아정신과 의사와의 면담과 포괄적인 임상심리심리 검사를 시행하여 진행된 결과를 처음으로 보고하는 것이라 할 수 있다. 그러나, 부모가 무관심하거나 경제적인 능력이 어렵거나 결손 가정의 아이들의 의뢰되는 경향이 있어, 기 초학력 미달의 원인이 이미 진단되어 문제를 확인한 경우는 제외되었을 가능성과 다각적인 학습지도에 반응하지 않는 문제가 비교적 더 심각한 지적장애 학생이 상대적으로 더 의뢰되었을 가능성, 보호자의 부정(denial)으로 평가에 응하 지 않은 아동의 경우에 대한 선택편견(selection bias)이 존 재할 수 있는 것이 이 보고를 일반학급의 기초학습부진 학 생에게 일반화하기 어려운 한계라 할 수 있을 것이다. 또한 구조화된 면접법에 의한 DSM-IV 진단을 하지 않아 누락된 공존질환의 존재 가능성도 있을 것으로 보인다.

\section{결 론}

본 연구는 교육청에서 의뢰된 일반학급에서 기초학습부진 이 지속되는 학생들을 대상으로 정신과적 면담 및 심리검사 를 통한 결과를 보고하였다. 본 연구 결과 기초학습부진으로 의뢰된 학생의 정신과적 진단이 지적장애가 $74.7 \%, \mathrm{ADHD}$ 가 $86.8 \%$, 우울증이 $21.1 \%$, 학습장애 $9.2 \%$ 로 파악되는 등 최소 한 개 이상의 정신의학적인 진단을 갖고 있었다. 우울, 불안 및 따돌림과 같은 문제도 공존하였다. 또한, 아동의 $\mathrm{K}-$ $\mathrm{PIC}$, 부모의 MMPI-2 프로파일이 각각 2개의 군집으로 구 분되어, 전반적인 정신병리 척도가 상승한 군이 존재함을 알 수 있었다.

학습장애나 $\mathrm{ADHD}$, 우울장애, 불안장애, 부모의 무관 심, 지적장애 모두 조기 발견 및 개입이 예후에 긍정적인 영 향 ${ }^{1,24,25)}$ 을 미친다. 본 연구에서 기초학습부진으로 의뢰된 학생들 중 정확한 진단과 치료적인 개입의 필요가 필요하지 않은 경우는 거의 없었다. 따라서, 학교에서 기초학습부진이 지속되는 학생들을 대상으로 정신과적인 진단 및 개입에 관 심을 기울여야 할 것으로 보인다. 한편, 이 연구는 일 광역 시에서 특정시기에 의뢰된 학생군을 대상으로 시행한 연구 로 기초학습부진 학생에 대한 보다 다양한 지역의 학생들 을 포함한 전향적인 연구가 필요할 것으로 보인다.

중심 단어:정신지체 · 학습장애· 우울증· 불안.

\section{References}

1) Hong K-EM. Korean Textbook of Child Psychiatry. Jungang Moonwha Co.;2005.

2) Shin SW, Kim BS, Seong DK, Jung Y, Yoo HJ, Cho SC. Survey of 
self-concept and depression-anxiety of the elementary school boys with learning disabilities. J Kor Acad Child Adolesc Psychiatry 2001;12:125-137.

3) Kim SP, Joung Y, Kim J, Hong SD. A preliminary study of children with learning disorder in Korea. J Kor Acad Child Adolesc Psychiatry 1996;7:247-257.

4) Torgesen JK, Wagner RK. Language abilities, reading acquisition, and developmental dyslexia: limitations and alternative views. J Learn Disabil 1992;25:577-581.

5) Nam MH. National wide Basic Academic Achievement Test (2006 year), 3rd grade-total. Seoul: Korean Institute for Curriculum and Evaluation;2007.

6) Lim MH, Kang JK, Lee JH, Kim HW. Clinical diagnosis and emotional and behavioral characteristeics study of children in a special education class in Korean elementary school. J Kor Acad Child Adolesc Psychiatry 2006;17:114-123.

7) Park KS, Chung DY, Jeong IS, Song YJ, Kim KO. A Study on Reliability and Validity of KISE-Basic Academic Achievement Test (Reading). J Emot Behav Disord 2005; 21:1-23.

8) Park KS, Chung DY, Jeong IS, Song YJ, Kim KO. A Study on Reliability and Validity of KISE-Basic Academic Achievement Test (Writing). Educ J Phys Mult Disabil 2006;47:245-263.

9) Kwak KJ, Park HW, Kim CT. A study for the standaridization of Korean WISC-III (I). Kor J Dev Psychol 2002;1:19-33.

10) Cho SC, Lee YS. Development of the Korean form of the Kovacs' Children's Depression Inventory. Kor J Neuropsychiatr Assoc 1990;29:943-956.

11) Lee WJ, Sin MS, Yoo IS, Bae ES, Park NW, Oh JY. The propensity to depression and anxiety in children J Kor Acad Fam Med 1998; 19:828-837.

12) Cho SC, Choi JS. Development of the Korean form of the State-Trait anxiety Inventory for Children Seoul J of Psychiatry 1989;14:150157.

13) So YK, Noh JS, Kim YS, Ko SG, Koh YJ. The Reliability and Validity of Korean Parent and Teacher ADHD rating scale. Kor J
Neuropsychiatr Assoc 2002;41:283-289.

14) Kim JW, Park KH, Choi MJ. Screening for Attention Deficit/Hyperactivity Disorder in Community Mental Health Services for Children. Kor J Neuropsychiatr Assoc 2004;43:200-208.

15) Kim YS, So YK, Noh JS, Choi NK, Kim SJ, Koh YJ. Normative data on the Korean ADHD Rating Scales (K-ARS) for Parents and Teacher. Kor J Neuropsychiatr Assoc 2003;42:352-359.

16) Hong CH, Kim SP, Kim JH, Hwang ST. Development and standardization of the Korean Personality Inventory for Children. Ment Health Res 2001;20:198-212.

17) Shin MS, Cho SZ, Chun SY, Hong K-E. A study of the development and standardization of ADHD Diagnostic system. J Kor Acad Child Adolesc Psychiatry 2000;11:91-99.

18) Ministry of Education, Science and Technology. Manual for AMPQ-II and follow-up management. Seoul: Ministry of Education, Science and Technology;2010.

19) Graham JR. MMPI-2: Assessing personality and psychopathology. New York: Oxford University Press;2006.

20) Vaughn S, Fuchs LS. Redefining learning disabilities as inadequate response to instruction: The promise and potential problems. Learn Disabil Res Pract 2003;18:137-146.

21) Kim DI, Lee DS, Shin JS. Introduction to Learning Disabiliies. 2nd ed. Seoul: Hakjisa;2009.

22) Wiener JM, Dulcan MK. Textbook of Child and Adolescent Psychiatry. 3rd ed. Washington DC: The American Psychiatric Publishing;2004.

23) Sung IK. Pediatic approach to early detection of learning disabilities. Kor J Pediatr;2008. p.911-921.

24) Multimodal Treatment Study of Children with ADHD. A 14-month randomized clinical trial of treatment strategies for attention-deficit/hyperactivity disorder. Arch Gen Psychiatry 1999;56:1073-1086.

25) Essex MJ, Kraemer HC, Slattery MJ, Burk LR, Boyce WT, Woodward HR, er al. Screening for childhood mental health problems: outcomes and early identification. J Child Psychol Psychiatry 2009; 50:562-570. 